Canadian

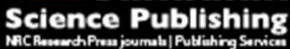

Applied Physiology, Nutrition, and Metabolism Physiologie appliquée, nutrition et métabolisme

\title{
Maternal and post-weaning folic acid supplementation interact to influence body weight, insulin resistance, and food intake regulatory gene expression in rat offspring in a sex-specific manner
}

\begin{tabular}{|r|l|}
\hline Journal: & Applied Physiology, Nutrition, and Metabolism \\
\hline Manuscript ID & apnm-2015-0503.R1 \\
\hline Manuscript Type: & Article \\
\hline Date Submitted by the Author: & $05-$-Nov-2015 \\
\hline Complete List of Authors: & $\begin{array}{l}\text { Huot, Pedro; University of Toronto, Department of Nutritional Sciences } \\
\text { Ly, Anna; University of Toronto, Department of Nutritional Sciences } \\
\text { Szeto, Ignatius; University of Toronto, Department of Nutritional Sciences } \\
\text { Reza-López, Sandra; University of Toronto, Nutritional Sciences } \\
\text { Cho, Daniel; University of Toronto, Department of Nutritional Sciences } \\
\text { Kim, Young-In; University of Toronto, Department of Nutritional Sciences; } \\
\text { University of Toronto, Department of Medicine; St. Michael's Hospital, } \\
\text { Keenan Research Centre for Biomedical Sciences; St. Michael's Hospital, } \\
\text { Division of Gastroenterology } \\
\text { Anderson, G. Harvey; University of Toronto, }\end{array}$ \\
\hline Keyword: & $\begin{array}{l}\text { folate / folic acid, food intake, insulin resistance, maternal } \\
\text { supplementation, body weight }\end{array}$ \\
\hline &
\end{tabular}

\section{SCHOLARONE" \\ Manuscripts}


Maternal and post-weaning folic acid supplementation interact to influence body weight, insulin resistance, and food intake regulatory gene expression in rat offspring in a sex-specific manner

Pedro S.P. Huot ${ }^{1}$, Anna Ly ${ }^{1}$, Ignatius M.Y. Szeto ${ }^{1}$, Sandra A. Reza-López ${ }^{1}$, Daniel Cho ${ }^{1}$, Young-In $\mathrm{Kim}^{1-4}$, and G. Harvey Anderson ${ }^{1 *}$

${ }^{1}$ Department of Nutritional Sciences, Faculty of Medicine, University of Toronto, Toronto, Canada, M5S 3E2

${ }^{2}$ Department of Medicine, Faculty of Medicine, University of Toronto, Toronto, Canada, M5G 2C4

${ }^{3}$ Keenan Research Centre for Biomedical Sciences of St. Michael's Hospital, Toronto, Canada, M5B 1W8

${ }^{4}$ Division of Gastroenterology, St. Michael's Hospital, Toronto, Canada, M5B 1W8

(Correspondence should be addressed to G. Harvey Anderson

Department of Nutritional Sciences

University of Toronto, Faculty of Medicine

150 College Street, FitzGerald Building Room 322

Toronto, ON, Canada M5S 3E2

Phone: 416 978-1832; Fax: 416-978-5882; Email: harvey.anderson@utoronto.ca)

Running Title: Effects of maternal and postnatal folic acid supplementation on body weight, insulin resistance, and food intake 
Abbreviations used: Agrp - Agouti-related protein; iAUC - incremental area under the curve; Lepr - leptin receptor Obrb isoform; Npy - neuropeptide Y; PAR - Predictive Adaptive Response hypothesis; Pomc - proopiomelanocortin; QUICKI - quantitative insulin sensitivity check index 


\begin{abstract}
Maternal intake of multivitamins or folic acid above the basal dietary requirements alters the growth and metabolic trajectory of rat offspring. We hypothesized that a modest increase in folic acid content in maternal diets would alter the offspring's metabolic phenotype and that these effects could be corrected by matching the folic acid content of the offspring's diet with the maternal diet. Female Sprague-Dawley rats were placed on a control or $2.5 \mathrm{x}$ folic acid supplemented diet prior to mating and during pregnancy and lactation. At weaning, pups from each maternal diet group were randomized to the control or $2.5 \mathrm{x}$ folic acid supplemented diet for 25 weeks. Male pups from dams fed the folic acid supplemented diet were 3.7\% heavier and had lower mRNA expression for leptin receptor (Lepr: 11\%) and Agouti-related peptide (Agrp: 14\%) than those from control-fed dams. In contrast, female pups from folic acid-supplemented dams were 5\% lighter and had lower Pomc (42\%), Lepr (32\%), and Agrp (13\%), but higher neuropeptide Y (18\%) mRNA expression than those from control-fed dams. Folic acid supplementation ameliorated these alterations induced by maternal folic acid supplementation in male pups and led to the lowest insulin resistance, but the effects were less in female pups and led to highest insulin resistance. In conclusion, maternal folic acid supplementation at $2.5 \mathrm{x}$ the control level was associated with alterations in body weight and hypothalamic gene expression in rat offspring in a sex-specific manner and some of these effects were attenuated by post-weaning folic acid supplementation.
\end{abstract}

Key Words: Folate/folic acid, food intake, insulin resistance, maternal supplementation, body weight 


\section{Introduction}

Folate, a water-soluble B vitamin, is important in facilitating one-carbon transfer reactions involved in DNA synthesis and DNA methylation, an important epigenetic process for gene expression, DNA integrity and stability, and chromatin modifications (Kim 2005). Folate deficiency during pregnancy has been linked to the development of neural tube and other congenital defects, adverse pregnancy outcomes, and cancers in the offspring (Duthie 2010; Marti-Carvajal et al. 2004; Ray et al. 2002). Conversely, periconceptional high dietary folate intake or folic acid (the synthetic form of folate) supplementation have been associated with a reduction in the risk of the adverse pregnancy and birth outcomes and offspring's health risk (French et al. 2003; Torrens et al. 2006). In particular, based on an overwhelming body of evidence (De Wals et al. 2008; Obican et al. 2010; Scholl 2008), folic acid supplementation has been recommended to women of reproductive age to reduce the risk of neural tube defects (Green 2002; Obican et al. 2010; Ray et al. 2002). Furthermore, mandatory folic acid fortification was implemented in Canada and US in 1998 to reduce the risk of neural tube defects (Olney and Mulinare 2002; Ray et al. 2002), which has led to a 15-50\% reduction in the rate of neural tube defects (De Wals et al. 2007; Mills and Signore 2004). As a result, the developing fetus in North America is exposed to a high level of folate and folic acid during the critical stage of metabolic and epigenetic programming. An emerging body of evidence from animal and clinical studies has suggested that excess folic acid intake during periconceptional period may have adverse effects on offspring's health risk (Kim 2007) including an increased risk of obesity and metabolic syndrome (Yajnik et al. 2008), an increased cancer risk (Ly et al. 2011), an increased risk of asthma and allergies (Kiefte-de Jong et al. 2012; Whitrow et al. 2009), increased ovarian cysts and mortality (Shorter et al. 2014), and altered behavior, such as increased repetitive behavior and hyperactivity (Barua et al. 2014; Shorter et al. 2014). The role of high folate intakes during 
pregnancy on the risk of birth outcomes, other than neural tube defects, and the development of chronic diseases in the offspring remains highly controversial.

We have previously shown that feeding female rats gestational diets containing non-toxic high levels of multivitamins (10x the control amounts in the AIN-93G diet) produces offspring that are obese, hypertensive, and insulin resistant, with increased body fat composition and disrupted expression of hypothalamic genes involved in food intake regulation when weaned to diets containing recommended vitamin levels (Cho et al. 2013b; Szeto et al. 2008; Szeto et al. 2009; Szeto et al. 2010). The observed altered physiology and metabolic phenotype in the offspring may be explained by the predictive adaptive response hypothesis, which states that altering the postnatal environment from that of the in utero will increase the risk of developing detrimental characteristics; conversely, matching the two environments will attenuate adverse effects (Gluckman and Hanson 2006).

The particular vitamin(s) responsible for the altered physiology and metabolic phenotype in the offspring associated with the high multivitamin maternal diet is not well characterized. However, we have recently shown that maternal folic acid supplementation at 10x the basal dietary requirement, either alone or in combination with vitamins $\mathrm{B}_{6}$ and $\mathrm{B}_{12}$, replicates the metabolic effects in the male offspring induced by high multivitamin maternal diets and alters offspring hypothalamic gene expression through changes in DNA methylation (Cho et al. 2015; Cho et al. 2013a). Furthermore, feeding male pups, but not female pups, the same diet containing multivitamins at 10x the control or folic acid at 10x the basal dietary requirement as their dams prevented them from developing the obesogenic phenotype, thereby supporting the predictive adaptive response hypothesis (Cho et al. 2013a; Cho et al. 2013b).

The Institute of Medicine's recommendation for the prevention of NTDs is periconceptional folic acid supplementation at 400 micrograms/day; however recommendation for those at high risk 
(e.g., family history, prior NTD birth, etc.) is up to $1-5 \mathrm{mg}$ folic acid/day (2.5 to $12.5 \mathrm{x}$ higher than the recommended dietary allowance) (Koren et al. 2008; Wilson et al. 2007). Also, folic acid supplementation at 1-5 mg/day is used in certain medical situations - e.g., patients with inflammatory arthritis and dermatitis on high dose anti-folate medications, such as methotrexate, are given folic acid 1-5 mg/day to prevent side effects of anti-folate medications (Shea et al. 2014). The multivitamin dose of 10x higher than recommended is not far from intake levels observed in pregnant women (2.5 to 7x higher) (Lagiou et al. 2005), and within the range of these higher recommendations. Furthermore, many women are taking additional supplements before and during pregnancy (Bailey et al. 2011; Sullivan et al. 2009) and, when combined with fortified foods, consume diets with several-fold the recommended intakes, and even beyond the upper levels (Colapinto et al. 2011). Therefore, the obsesogenic effects associated with the maternal diet containing multivitamins at 10x the recommended amounts or folic acid at 10x the basal dietary requirement are likely nutritionally and physiologically relevant. Nevertheless, it is unknown if these obesogenic effects occur at lower maternal supplemental doses of folic acid, which fall within a conventionally considered more physiological range.

Given this consideration, the objective of the present study was to determine the effect of a modest supplemental level of folic acid $(2.5 \mathrm{x}$ the basal dietary requirement) folic acid added to the maternal and post-weaning diets, on body weight, insulin resistance, and food intake regulatory gene expression in the hypothalamus of the offspring. We posited that a modest increase in folic acid content alone in maternal diets would alter the offspring's metabolic phenotype and that these effects can be corrected by matching the folic acid content of the offspring's diet with the maternal diet.

\section{Material and methods}

Animals, diets, and experimental design 
This study was approved by the Animal Care Committee of the University of Toronto and was conducted in strict accordance with the Regulations of the Animals for Research Act in Ontario and the Guidelines of the Canadian Council on Animal Care. Male and female Sprague-Dawley rats at 8 weeks of age were purchased from Charles River Laboratories (St. Constant, Quebec, Canada). During breeding, female rats were housed in pairs with males, while during pregnancy and lactation female rats were housed singly. Female rats were randomized to receive an amino acid-defined diet (Dyets, Bethlehem, PA) (Walzem and Clifford 1988) containing either $2 \mathrm{mg}$ (control; basal dietary requirement) or $5 \mathrm{mg}$ (2.5x supplemental level) folic acid/ $\mathrm{kg}$ diet three weeks prior to mating, and throughout pregnancy and lactation as previously described (Ly et al. 2011; Sie et al. 2009). Male rats used for breeding were placed on the same diet as the female breeding mates. At weaning, 15 male and 15 female pups from each maternal diet group were randomized to receive either the control or the $2.5 \mathrm{x}$ folic acid supplemented diet for 25 weeks and dually-housed. This resulted in 4 pup groups for each sex ( $n=15$ males and $n=15$ females/group) based on dam diet-pup diet matches: control-control, control-2.5x folic acid supplementation, $2.5 \mathrm{x}$ folic acid supplementation-control, and 2.5x folic acid supplementation-2.5x folic acid supplementation diets.

The use of amino acid-defined diets constitutes a standard method for providing supplemental dietary folic acid in a predictable manner (Walzem and Clifford 1988) and have been used in previous studies of dietary folic acid intervention in rodents including those that examined the effect of maternal folic acid supplementation on offspring's cancer risk (Ly et al. 2011; Sie et al. 2011). The control diet, which provides $2 \mathrm{mg}$ folic acid/ $\mathrm{kg}$ diet and $4000 \mathrm{kcal} / \mathrm{kg}$ diet, is generally accepted as the basal dietary requirement for rats (National Research Council (U.S.). Subcommittee on Laboratory Animal Nutrition. 1995). This level of folic acid expressed relative to caloric content very closely approximates the recommended dietary allowance of $0.4 \mathrm{mg}$ dietary folate equivalent in humans consuming a daily average of $2000 \mathrm{kcal}$ (IOM 1998) and thus, was selected to parallel the 
recommended dietary allowance for folate in humans. The supplemented diet containing $5 \mathrm{mg}$ folic $\mathrm{acid} / \mathrm{kg}$ diet (2.5x the basal dietary requirement) was selected to approximate the likely average total folate intake $(\cdot 0.8-1 \mathrm{mg}$ folic acid/day or $2-2.5 \mathrm{x}$ recommended dietary allowance) from fortified foods and multivitamin containing $0.4 \mathrm{mg}$ folic acid in North American populations in the postfortification era (Kim 2008). Also, the 2.5x supplemental level of folic acid is in line with the mean intake of folic acid in pregnant women (Lagiou et al. 2005) and represents the recommended dose of folic acid supplementation (0.4-1.0 $\mathrm{mg}$ folic acid/day) for all women planning a pregnancy or capable of becoming pregnant (Wilson et al. 2007). Detailed composition of the diets has been previously published (Walzem and Clifford 1988): briefly, the diets per kg contained cellulose (50 g), carbohydrates (622 g), fat (100 g), L-amino acids (171 g), and mineral, salt, and vitamin mix. Diets and water were provided ad libitum.

After weaning, food intake and body weight were measured on a weekly basis starting from 1 week to 25 weeks post-weaning. At 25 weeks post-weaning, rats were fasted overnight for $10 \mathrm{~h}$ and then killed by carbon dioxide inhalation followed by cervical dislocation. Blood samples were collected and stored for analysis.

\section{Glucose Loading}

Blood glucose was measured after oral glucose loading at 20 weeks post-weaning as previously described (Szeto et al. 2008; Szeto et al. 2009). Rats were fasted overnight for $10 \mathrm{~h}$ prior to gavage $(0.375 \mathrm{~g}$ glucose $/ \mathrm{mL}, 5 \mathrm{~g}$ glucose $/ \mathrm{kg}$ body weight $)$. Blood glucose concentrations were determined at 0 (prior to gavage), 15, 30, 45 and 60 min later using a commercial glucometer (MediSense Precision Xtra) and blood withdrawn from the capillary bed of the tail tip.

\section{Folate concentration and insulin analysis}


Plasma and liver folate concentrations were determined by a standard microbiological microtiter plate assay using Lactobacillus casei (Molloy and Scott 1997; Sie et al. 2009); the intraand inter-assay coefficient of variation were both $<0.5 \%$. Plasma insulin concentrations were analyzed by Insulin Enzyme Immunoassay (Catalogue \#: 80-INSRT-E01, Alpco Diagnostics, Salem, $\mathrm{NH}$ ) with an assay sensitivity limit of $0.124 \mathrm{ng} / \mathrm{mL}$ (Szeto et al. 2011).

\section{RNA extraction and real-time RT-PCR}

RNA from the hypothalamus was extracted as previously described (Szeto et al. 2010). Briefly, whole rat brains were removed rapidly at necropsy and immediately frozen on dry ice, and then stored at $-80^{\circ} \mathrm{C}$. The brains were thawed on ice before removal of the hypothalamus. Each hypothalamic block was homogenized by tissue Ruptor (Qiagen Tech., Mississauga, ON) and total RNA was isolated using Trizol reagent/chloroform extraction as per the manufacturer's protocol (Invitrogen, Grand Island, NY).

The oligonucleotide primer and fluorogenic probe sets for cDNA synthesis and $\operatorname{Taqman}^{\mathrm{TM}}$ real time RT-PCR were purchased from ABI (Applied Biosystems Inc., Foster City, CA): proopiomelanocortin (Pomc, Assay ID: Rn00595020_m1); leptin receptor Obrb isoform (Lepr, Assay ID: Rn01433205_m1); neuropeptide Y (Npy, Assay ID: Rn01410146_m1); Agouti-related protein (Agrp, Assay ID: Rn01431703_ml); and Gapdh (Assay ID: Rn99999916_s1) as endogenous control. Synthesis of cDNA was performed on an ABI Gene Amp PCR System 2700 using the following incubation conditions: $10 \mathrm{~min}$ at $25^{\circ} \mathrm{C}$, followed by $120 \mathrm{~min}$ at $37^{\circ} \mathrm{C}$ (Szeto et al. 2010). Real-time RT-PCR and relative quantification were performed on the ABI PRISM 7000 Sequence Detection System (SDS). The cycle conditions were: $50^{\circ} \mathrm{C}$ for $2 \mathrm{~min}, 95^{\circ} \mathrm{C}$ for $10 \mathrm{~min}$, followed by 35 cycles of $95^{\circ} \mathrm{C}$ for $15 \mathrm{sec}, 60^{\circ} \mathrm{C}$ for $1 \mathrm{~min}$. Commonly used housekeeping genes, Gapdh, $\beta_{2}$ microglobulin and 18-s $r R N A$, were screened in a preliminary study and Gapdh was selected as the 
housekeeping gene for this study because it remained constant under our experimental conditions. Results are presented as fold-change in gene expression, determined by the $2^{-\Delta \Delta \mathrm{CT}}$ method (Livak and Schmittgen 2001) and using the mean expression of the control-control diet group as reference.

\section{Statistical analysis}

Statistical analyses were performed using the SAS System for Windows (Version 9.3, SAS Institute, Cary, NC). Results are expressed as mean \pm SE. All significance tests were two-sided and were considered significant at $P<0.05$.

Body weight data from 1 week to 25 weeks post-weaning were analyzed by PROC MIXED repeated measures ANOVA (dam diet, pup diet and time as factors). Glucose loading data from 0 60 min were also analyzed by PROC MIXED repeated measures ANOVA (dam diet, pup diet and time as factors).

Blood glucose concentrations from 0 to $60 \mathrm{~min}$ from glucose load were plotted to calculate incremental area under the curve (iAUC). Insulin resistance index was calculated as fasting glucose multiplied by fasting insulin (Cutfield et al. 2003; Szeto et al. 2011). Quantitative insulin sensitivity check index (QUICKI) was calculated as the inverse of the sums of log-transformed fasting insulin and glucose (QUICKI $=1 /[\log ($ fasting insulin $)+\log ($ fasting glucose $)]($ Cacho et al. 2008)

Glucose, glucose iAUC, insulin, insulin resistance index, QUICKI, plasma and liver folate status, and hypothalamic mRNA gene expression were analyzed by general linear model two-way ANOVA (dam diet and pup diet as main factors). Variables with non-normal distribution (insulin resistance index) were transformed to their natural logarithm for analysis as indicated in their respective table. For mRNA data, each gene's relative quantification values were normalized to Gapdh values and analyzed by comparing the hypothalamic gene expression among all groups. 
When an interaction was significant, post-hoc comparisons were analyzed by general linear model two-way ANOVA with Tukey's pair-wise multiple comparisons test.

\section{Results}

\section{Litter size, body weight, and food intake}

The maternal diet did not affect litter size $(9.9 \pm 0.8$ and $9.0 \pm 0.6$ pups per litter in the control and the $2.5 \mathrm{x}$ folic acid supplemented diet groups, respectively, $\mathrm{P}=0.41$ ). Maternal food intake during pregnancy was not significantly different between the two dietary groups (data not shown). Neither the maternal nor pup diet had independent effects on body weight in all pups. However, significant time effects $(\mathrm{P}<0.0001)$ and interactions between the maternal diet and time $(\mathrm{P}<0.0001)$ were observed for both sexes, indicating that the effect of the maternal diet on body weight increased over time (Figure 1A and Figure 1B). Similarly, significant interactions between the pup diet and time $(\mathrm{P}<0.05)$ were observed for males, but not for females, indicating that the pup diet effect on body weight increased over time (Figure 1A).

The interaction between the folic acid content of the maternal diet and time $(\mathrm{P}<0.0001)$ was such that the rate of change in body weight was higher in all male pups born to the dams fed the $2.5 \mathrm{x}$ folic acid supplemented diet from 8 weeks to 25 weeks post-weaning compared with male pups born to the dams fed the control diet. Of these male pups from the dams fed the $2.5 \mathrm{x}$ folic acid supplemented diet, those weaned to the control diet had the highest body weight. This body weight increase did not occur in male pups from the dams fed the $2.5 \mathrm{x}$ folic acid supplemented diet that were weaned to the same folic acid supplemented pup diet. In contrast to the male offspring, the rate of change in body weights over time (maternal diet $\times$ interaction, $\mathrm{P}<0.0001$ ) was lower in female pups born to the dams fed $2.5 \mathrm{x}$ folic acid supplemented diet, beginning at 9 weeks to 25 weeks postweaning, compared with female pups born to the dams fed the control diet. Although the effect was 
not as strong as in male pups of the same dietary group, female pups from the dams fed the $2.5 \mathrm{x}$ folic acid supplemented diet and then weaned to the control post-weaning diet had the lowest weight gain with time, while female pups from the dams fed the $2.5 \mathrm{x}$ folic acid supplemented diet and then weaned to the same folic acid supplemented post-weaning diet had body weights closer to female pups born to the dams fed the control diet and then weaned to the same control post-weaning diet.

\section{Plasma and liver folate concentrations}

Plasma folate concentrations of male and female pups at 25 weeks post-weaning were affected independently by the folic acid content of the pup $\operatorname{diet}(\mathrm{P}<0.001)$ and by an interaction between the folic acid content of both the dam and pup diets (Table 1). Independent of the maternal diet, both male and female pups weaned to the $2.5 \mathrm{x}$ folic acid supplemented pup diet had higher plasma folate concentration than those weaned to the control pup diet. The interaction between the dam and pup diets occurred in plasma folate for both male $(\mathrm{P}<0.001)$ and female $(\mathrm{P}<0.01)$ pups. Male pups, but not female pups, born to the dams fed the $2.5 \mathrm{x}$ folic acid supplemented diet and then weaned to the control pup diets had lower plasma folate concentrations than those born to the dams fed the control diet and then maintained on the same control pup diet. In contrast, both male and female pups from the dams fed the $2.5 \mathrm{x}$ folic acid supplemented diet and then weaned to the same folic acid supplemented pup diet had higher plasma folate concentrations than those from the dams fed the control diet and then weaned to the same control post-weaning diet.

Liver folate concentrations in both sexes were affected by the folic acid content of the dam $(\mathrm{P}<0.05)$ and pup $(\mathrm{P}<0.0001)$ diets without significant interactions (Table 1). Both male and female pups born to the dams fed the $2.5 \mathrm{x}$ folic acid supplemented diet had higher liver folate concentrations than those from the dams fed the control diet. Both male and female pups fed the $2.5 \mathrm{x}$ 
folic acid supplemented pup diet had higher liver folate concentrations than those fed the control pup diet.

\section{Glucose and insulin analyses}

Fasting blood glucose concentrations at 25 weeks post-weaning were affected by the pup diet $(\mathrm{P}<0.05)$ without any dam diet or interaction effects in male, but not female, pups. Male pups fed the 2.5x folic acid supplemented pup diet had lower blood glucose concentrations at fasting than those fed the control pup diet (Figure 2A, Table 1). There was no independent effect of the dam diet on fasting blood glucose concentrations $(\mathrm{P}<0.10)$. However, the blood glucose concentration 15 min after glucose loading at 20 weeks post-weaning demonstrated higher glucose responses in male pups from the dams fed the $2.5 \mathrm{x}$ folic acid supplemented diet, regardless of the folic acid content in the pup diet, compared with those from the dams fed the control diet $(\mathrm{P}<0.01)$ (Figure 2A). Neither the dam nor pup diet effects were observed on blood glucose concentrations at times 30,45 , or 60 min during glucose loading (Figure 2A) or the iAUC (data not shown). In female pups, there were no significant differences in blood glucose response to glucose loading at any time point (Figure 2B, Table 1) or in the iAUC (data not shown).

Fasting plasma insulin concentrations in both male and female pups were affected by the pup $\operatorname{diet}(\mathrm{P}<0.05)$, but not by the dam diet or interactive effects (Table 1). Male pups fed the 2.5x folic acid supplemented pup diet had lower plasma insulin concentrations that those fed the control pup diet. In contrast, female pups fed the $2.5 \mathrm{x}$ folic acid supplemented pup diet had higher plasma insulin concentrations than those fed the control pup diet.

The folic acid content of the dam diet had no independent effect (Table 1) on either insulin resistance index or insulin sensitivity index (QUICKI) in the offspring. However, in male, but not female, offspring the pup diet significantly influenced insulin resistance index $(\mathrm{P}<0.05)$ and QUICKI 
$(\mathrm{P}=0.05)$. Male pups, irrespective of the folic acid content in the dam diet, weaned to the $2.5 \mathrm{x}$ folic acid supplemented pup diet had a lower insulin resistance index than those weaned to the control pup diet. These findings were corroborated by the higher insulin sensitivity observed in male pups fed the $2.5 \mathrm{x}$ high folic acid supplemented pup diet than those fed the control pup diet. Furthermore, an interaction effect between the dam and pup diets was observed for insulin resistance index $(\mathrm{P}<0.05)$ and QUICKI $(\mathrm{P}<0.05)$ in male pups, and insulin resistance index $(\mathrm{P}<0.05)$ in female pups (Table 1). Male pups from the dams fed the $2.5 \mathrm{x}$ folic acid supplemented diet and then weaned to the $2.5 \mathrm{x}$ folic acid supplemented pup diet exhibited the lowest insulin resistance index and the highest insulin sensitivity, whereas those from the dams fed the $2.5 \mathrm{x}$ folic acid supplemented diet and then weaned to the control pup diet showed the highest insulin resistance index and the lowest insulin sensitivity. The opposite was observed in female pups born to the dams fed the $2.5 \mathrm{x}$ folic acid supplemented diet, where pups fed the $2.5 \mathrm{x}$ folic acid supplemented pup diet had the highest insulin resistance index and those fed the control pup diet had the lowest insulin resistance index.

\section{Hypothalamic gene expression}

Hypothalamic gene expression of the selected regulatory neuropeptides governing food intake was altered in both male and female pups by the folic acid content in both the dam and pup diets either alone or through interactions. However, the responses in hypothalamic gene expression to the folic acid level of the maternal and pup diets were different between male and female pups.

In male pups born to the dams fed $2.5 \mathrm{x}$ folic acid supplemented diet, expression was lower for the Lepr $(\mathrm{P}<0.05)$ and Agrp $(\mathrm{P}<0.05)$ genes compared with those born to the dams fed the control diet, but no differences were observed for Pomc or Npy expression (Table 2). Irrespective of the maternal diet, male pups weaned to the $2.5 \mathrm{x}$ folic acid supplemented pup diet had higher expression for the Lepr $(\mathrm{P}=0.001)$ and $\operatorname{Agrp}(\mathrm{P}<0.0001)$ genes compared with those on the control pup diet, but 
no differences in expression for the Pomc and Npy genes were observed between the two pup diets (Table 2). No significant interactions between the maternal and post-weaning diets in modulating Lepr and Agrp gene expression were observed. Although neither the maternal nor post-weaning diet had significant independent effects, Pomc and Npy gene expression was affected by an interaction between the folic acid content of the dam and pup diets ( $\mathrm{P}<0.05$ and $\mathrm{P}<0.05$, respectively) in a manner that suggests that the effect of the pup diet was opposite and dependent on the dam diet (Table 2). The 2.5x folic acid dam diet resulted in lower Pomc and Npy gene expression in male pups compared with the control dam diet if the pups were weaned to the control pup diet. However, if male pups were fed the $2.5 \mathrm{x}$ folic acid supplemented pup diet, then those born to the dams fed the 2.5x folic acid supplemented diet had higher expression of these genes than those born to the dams fed the control diet.

In female pups, both the dam and pup diets independently affected the expression of the selected genes except for the pup diet on Pomc expression (Table 2). The 2.5x folic acid supplemented maternal diet was associated with lower expression for the Pomc $(\mathrm{P}<0.005)$, Lepr $(\mathrm{P}<0.0005)$, and $\operatorname{Agrp}(\mathrm{P}=0.05)$ genes but higher for the Npy gene $(\mathrm{P}<0.05)$ compared with the control maternal diet, irrespective of the pup diet (Table 2). In contrast, the 2.5x folic acid supplemented pup diet was associated with high gene expression for the Lepr $(\mathrm{P}<0.0001), \operatorname{Agrp}$ $(\mathrm{P}<0.0001)$, and Npy $(\mathrm{P}<0.0005)$ genes, but not the Pomc gene, compared with the control pup diet, irrespective of the maternal diet (Table 2). There was an interaction effect between the dam and pup diets $(\mathrm{P}<0.05)$ such that female pups born to the dams fed the $2.5 \mathrm{x}$ folic acid supplemented diet and then weaned to the same folic acid supplemented pup diet had the highest expression of the Npy gene compared with the other three dietary groups (Table 2). There were no interaction effects between the maternal and pup diets observed in the expression of the Pomc, Lepr, or Agrp genes. 


\section{Discussion}

Our data demonstrate that a modest supplemental level of folic acid (2.5x the basal dietary requirement) in the maternal diets was associated with higher body weights in male pups but matching the folic acid content in the post-weaning diet to that in the maternal diet largely abolished this effect. Although maternal folic acid supplementation generally had no effect on blood glucose concentrations or response to glucose loading in male pups, post-weaning folic acid supplementation at the same level significantly decreased blood glucose concentrations. In contrast to the lack of effect associated with maternal folic acid supplementation, post-weaning folic acid supplementation significantly reduced plasma insulin concentrations and insulin resistance index and increased insulin sensitivity. The effects of maternal and post-weaning folic acid supplementation, however, were significantly different in female pups compared with those in male pups. Maternal folic acid supplementation was associated with lower weight gain in female pups and post-weaning folic acid supplementation attenuated this effect. Maternal and post-weaning folic acid supplementation had no effects on blood glucose concentration and response to glucose loading, plasma insulin concentration, insulin resistance index, and insulin sensitivity in female pups except that post-weaning folic acid supplementation increased plasma insulin concentration. Furthermore, interactions between maternal and post-weaning folic acid supplementation in modifying insulin resistance index and insulin sensitivity were different between male and female pups. While maternal and post-weaning folic acid supplementation interacted in a manner to reduce insulin resistance index and increase insulin sensitivity in male pups, the opposite effect on insulin resistance index was observed in female pups.

The effects of maternal folic acid supplementation at $2.5 \mathrm{x}$ the basal dietary requirement prior to and during pregnancy and lactation in male pups are similar to those observed after feeding dams gestational diets containing all multivitamins at 10x the control amounts in the AIN-93G diet (Szeto et al. 2008), methyl vitamins (folate, vitamin $B_{6}$ and $B_{12}$ ) at 10x the control levels (Cho et al. 2015) 
or folic acid alone at 10x the control amount in male (Cho et al. 2013a; Cho et al. 2013b). Previous results with the high multivitamin maternal diet show that the offspring exhibited increased food intake, body weight, and fat pad mass, and had developed characteristics of the metabolic syndrome in male pups (Szeto et al. 2008). Similarly, the lower weight gain observed in female pups from the $2.5 \mathrm{x}$ folic acid supplemented diet is consistent with the results of feeding dams gestational diets containing folic acid at 10x the control level (Huot et al. 2013). We recently showed that folic acid is one of the vitamins responsible for these observed effects because folic acid supplementation alone at 10x the basal dietary requirement in the dam diet replicated the obesogenic phenotype in the male offspring (Cho et al. 2013a). However, previous studies used a dose of folic acid (10x the basal dietary requirement) that is much higher than typically recommended to pregnant women (up to $2.5 \mathrm{x}$ the recommended dietary allowance (Lagiou et al. 2005)). Therefore, questions concerning the nutritional and physiological relevance and applicability to humans were raised. We therefore carefully considered and deliberately selected the supplemental level of folic acid at the $2.5 \mathrm{x}$ the basal dietary requirement in the present study to reflect the average postfortification total folate intake from fortified foods and multivitamin containing $0.4 \mathrm{mg}$ folic acid in North America ( 0.8$1.0 \mathrm{mg}$ /day or $2.5 \mathrm{x}$ the recommended dietary allowance) and to approximate the recommended dose of folic acid supplementation (up to $1.0 \mathrm{mg}$ /day or $2.5 \mathrm{x}$ the recommended dietary allowance) for women at reproductive age (Wilson et al. 2007). The effects of this modest supplemental level of folic acid were much more subtle. Nevertheless, we were able to demonstrate that folic acid supplementation at the level attainable in humans and at a currently recommended consumption level by women during pregnancy induced phenotypic and physiological changes in rat offspring. Because of inherent differences in folate metabolism between human and rats (Bailey and Ayling 2009; Wright et al. 2007), our selected supplemental folic acid level may not accurately reflect the corresponding level in humans. Folic acid is biotransformed by dihyrofolate reductase in 
the liver and to a lesser degree in the intestine, before it can enter the folate cycle (Wright et al. 2007). Recent evidence suggests that rats, unlike humans, have a comparatively high dihydrofolate reductase activity (Bailey and Ayling 2009; Wright et al. 2007). Consequently, a higher dose of folic acid is likely required to elicit similar physiological effects of folic acid in rats relative to humans in order to assess the impact of systemic exposure of folic acid (Bailey and Ayling 2009; Wright et al. 2007). Therefore, the selected supplemental level of folic acid in rats in the present study likely achieved much lower plasma concentrations of folic acid than would have been achieved by the equivalent supplemental level of folic acid in humans. Nevertheless, this modest maternal and postweaning supplemental level of folic acid was significantly associated with phenotypic and metabolic changes in the offspring.

Our study demonstrated the protective effects of matching the folic acid content of the pup diet to the dam diet, thereby rendering support for the predictive adaptive response hypothesis (Gluckman and Hanson 2006), which states that a mismatch between the intrauterine and postnatal environments increases the risk of developing non-communicable adult diseases, but matching the two environments reduces this risk (Gluckman and Hanson 2006; Hanson et al. 2011). In the present study, the $2.5 \mathrm{x}$ folic acid supplemented pup diet prevented weight gain in male pups, and attenuated the slower weight gain in female pups, born to the dams fed the $2.5 \mathrm{x}$ folic acid supplemented diet. Furthermore, matching the folic acid content of the pup diet to the $2.5 \mathrm{x}$ supplemental level of the maternal diet was associated with lower and higher fasting insulin resistance index in male and female pups, respectively, despite no main effect of maternal diet. These findings are consistent with our previous observations made in rat models of gestational high multivitamin, high methyl vitamin, or high folic acid supplementation at 10x the control amounts diets (Cho et al. 2015; Cho et al. 2013a; Cho et al. 2013b). In contrast, a methyl-supplemented post-weaning diet fed to viable yellow agouti mice failed to alter the offspring's coat colour and did not protect the yellow mice offspring 
against premature obesity or development of metabolic disease (Warzak et al. 2015). However, this mouse study used offspring borne to dams fed a control diet, and therefore, the methyl-supplemented post-weaning diet was actually the mismatched diet. The relationship between the maternal diet and the post-weaning diet may be an important factor in determining the health trajectory of the offspring.

Sex differences in response to maternal vitamin and/or folic acid supplementation have been observed in our previous studies. Feeding a high multivitamin diet at 10x the recommended amount to dams during gestation resulted in higher body weights in male pups (Szeto et al. 2008; Szeto et al. 2009), but not in female pups, weaned to the control diet (Szeto et al. 2008; Szeto et al. 2011). In contrast, both sexes showed the obesogenic phenotype when fed the high multivitamin post-weaning diet (Szeto et al. 2009). Interestingly, maternal folic acid supplementation at 10x the control amount was associated with higher body weights in male pups (Cho et al. 2013a) but lower body weights in female pups (Huot et al. 2013). Sex differences were also observed in a recent study of the same design that examined the effect of maternal folic acid supplementation on colorectal cancer risk in the offspring. Compared to pups born to the dams fed the control diet, male pups from the dams fed the $2.5 \mathrm{x}$ folic acid supplemented diet had higher body weights from weaning until 31 weeks postweaning (Sie et al. 2011), while female pups from the dams fed the $2.5 \mathrm{x}$ folic acid supplemented diet had lower body weights at both weaning and 25 weeks post-weaning (Sie et al. 2009). Therefore, it seems that maternal folic acid supplementation may have different effects on female pups, depending on whether it is supplemented alone or in conjunction with other vitamins (Kiefte-de Jong et al. 2012; Yajnik et al. 2008). Nevertheless, mechanisms underlying the observed sex differences in phenotypic and metabolic outcomes associated with maternal folic acid supplementation remain to be elucidated. 
Sex differences were also observed in the expression of the selected 4 hypothalamic genes regulating food intake: anorexigenic Pomc and Lepr (genes that suppress food intake) and orexigenic Npy and Agrp (genes that promote food intake). Male pups born to the dams fed the 2.5x folic acid supplemented diet had higher body weights but lower expression of the Lepr and Agrp genes. In contrast, female pups from the dams fed the $2.5 x$ folic acid supplemented diet had lower body weights, lower expression of the Pomc, Lepr, and Agrp genes and higher expression of the Npy gene. Post-weaning folic acid supplementation increased the expression of the Lepr and Agrp genes in male pups and of the Lepr, Npy, and Agrp genes in female pups. Based on the body weight data, we expected that male pups would have higher, while female pups would have lower, food intake. Since there were no differences in food intake, this would suggest that other factors may be involved in explaining the observed body weight results, such as altered energy expenditure. The lack of differences in food intake, however, is consistent with our data from female offspring born to dams fed the 10x folic acid supplemented diet (Huot et al. 2013), but not with our data from male pups from the same maternal folic acid supplemented diet (Cho et al. 2013a) that had higher food intake associated with higher body weight gain. We previously reported that male offspring had lower expression of the Pomc gene when dam and pup diets were supplemented with folic acid at 10x the control amount (Cho et al. 2013a). Similarly, male offspring from high multivitamin fed dams had lower expression of the Pomc and brain-derived neurotrophic factor ( $B d n f$, another anorexigenic neuropeptide) genes, concomitant with higher weight gain and food intake, compared with those from control dams (Cho et al. 2013b).

\section{Limitations}

We did not investigate potential mechanisms by which maternal and post-weaning folic acid supplementation influence offspring's body weights and metabolic and physiologic changes in the 
present study. Although we examined the effect of maternal and post-weaning folic acid supplementation on gene expression of 4 hypothalamic genes governing food intake, a more comprehensive interrogation of genes critical for optimal metabolism and physiology of the fetal and postnatal development and growth is warranted. Given the critical role of folic acid supplementation on DNA methylation, the effect of maternal and post-weaning folic acid supplementation on promoter CpG island DNA methylation of critical genes, which inversely regulate gene expression, is of great interest. In this regard, we have recently shown that maternal or post-weaning folic acid supplement at 10x the basal dietary requirement induced changes in the expression of genes governing feeding-related neuropeptides in male offspring, which was associated with DNA hypomethylation of the Pomc promoter (Cho et al. 2013a). Furthermore, Pomc-specific DNA methylation was positively associated with the glucose response of male offspring to a glucose load.

Another limitation was that the study was relatively short to allow for the development of the full consequences of folic acid supplementation. Although modest changes we observed, we expect that given a longer duration of time these changes would have increased based on the following information. The significant interaction effect between time and diet on body weight supported that the effect that diet had on body weight increased as time progressed. Our previous study that used an obesogenic post-weaning diet reported that offspring from dams fed high multivitamin gestational diets had an $8 \%$ increase in body weight compared to control offspring at 7 weeks post-weaning; however, at 48 weeks post-weaning, the high multivitamin offspring had a $37 \%$ increase in body weight compared to control offspring (Szeto et al. 2009). Thus, the narrow changes observed in our study may continue to increase in range if more time had elapsed in the study.

\section{Significance}


Folate intake and blood levels in North America have significantly increased over the past decade. This rise is due to the drastic increase in dietary folate intake from mandatory folic acid fortification (Pfeiffer et al. 2007) aimed at reducing the rate of neural tube defects and also to the consumption of supplemental folic acid by up to $30-40 \%$ of the North American population (Bailey et al. 2010). Furthermore, women of childbearing age are routinely advised to take $0.4-1.0 \mathrm{mg}$ of folic acid for the prevention of neural tube defects (Wilson et al. 2007). These facts suggest that intrauterine exposure of the developing fetus to folate and folic acid has significantly increased in North America, for which only limited information concerning its effects on offspring's health outcomes and disease risk exists. Epigenetic and metabolic programming takes place during embryogenesis, which is highly susceptible to changes in the intrauterine environment, and dysregulation or aberration of epigenetic and metabolic programming during this stage may influence the development of chronic diseases later in adulthood (Gluckman et al. 2008; Waterland and Michels 2007). Our data suggest, for the first time, that maternal folic acid supplementation at the level equivalent to the average postfortification total folate intake in North America and to that recommended to women at reproductive age can influence body weights, insulin resistance, and the expression of genes governing food intake in a sex-dependent manner. Our study corroborates the findings from a recent clinical study, which suggests high maternal folate and folic acid intake was associated with obesity and insulin resistance in the offspring (Yajnik et al. 2008). At birth, folate intake was positively associated with birth weight, birth length, and head circumference and these effects were greater in boys than girls (Rao et al. 2001). At the age of six, more children born to the folic acid-supplemented mothers were obese and insulin resistant compared with those born to the mothers on a control diet. Our study provides proof-of-principle evidence that maternal folic acid supplementation can alter body weights and insulin resistance in the offspring and provides a framework for future preclinical and clinical studies aimed at elucidating this important issue. 


\section{Conclusion}

In conclusion, maternal folic acid supplementation $(2.5 \mathrm{x}$ the basal dietary requirement $)$ at the level equivalent to the average postfortification total folate intake in North America and to that recommended to women at reproductive age was associated with changes in body weights, insulin resistance, and expression of genes involved in food intake regulation in the offspring in a sexspecific manner, and matching the folic acid level in the post-weaning diet to that in the maternal diet attenuated many of these effects. Some of these effects were similar to those observed with a high multivitamin supplemented maternal diet and with maternal folic acid supplementation at 10x the control amount, suggesting that folic acid content in maternal diet might be a critical determinant of these effects. Given the drastically increased intrauterine and early life exposure to folic acid in North America, future studies are warranted to clarify the effects of maternal and postnatal folic acid supplementation on the risk of insulin resistance and metabolic syndrome in the offspring and associated mechanisms underlying these effects.

\section{Conflict of interest statement}

The authors declare that there are no conflicts of interest.

\section{Acknowledgements}

The authors thank Jiuhua Duan for his technical assistance with this research. This research was supported by the Canadian Institutes of Health Research (CIHR) (Grant \#: 14126, Y.I.K.), the CIHR - Institute of Nutrition, Metabolism and Diabetes Strategic Initiative: "Excellence, Innovation and Advancement in the Study of Obesity and Healthy Body Weight" (Grants \#: OOP-77980 and MOP-93624, G.H.A.). Support also provided by the Ontario Graduate Scholarships (P.S.P.H.), the 
CIHR Canada Graduate Scholarships Master's Award (A.L.), the Consejo Nacional de Ciencia y Tecnologia (Mexico) (S.A.R.L.), the National Sciences and Engineering Research Council of Canada (NSERC) Postgraduate Doctoral Scholarship (I.M.Y.S.), and the NSERC Undergraduate Research Award (D.C.). 


\section{References}

Bailey, R.L., Dodd, K.W., Gahche, J.J., Dwyer, J.T., McDowell, M.A., Yetley, E.A., Sempos, C.A., Burt, V.L., Radimer, K.L., and Picciano, M.F. 2010. Total folate and folic acid intake from foods and dietary supplements in the United States: 2003-2006. Am J Clin Nutr 91: 231-7.

Bailey, R.L., Gahche, J.J., Lentino, C.V., Dwyer, J.T., Engel, J.S., Thomas, P.R., Betz, J.M., Sempos, C.T., and Picciano, M.F. 2011. Dietary supplement use in the United States, 2003-2006. J Nutr 141: 261-6.

Bailey, S.W. and Ayling, J.E. 2009. The extremely slow and variable activity of dihydrofolate reductase in human liver and its implications for high folic acid intake. Proc Natl Acad Sci U S A 106: 15424-9.

Barua, S., Chadman, K.K., Kuizon, S., Buenaventura, D., Stapley, N.W., Ruocco, F., Begum, U., Guariglia, S.R., Brown, W.T., and Junaid, M.A. 2014. Increasing maternal or post-weaning folic acid alters gene expression and moderately changes behavior in the offspring. PLoS One 9: e101674.

Cacho, J., Sevillano, J., de Castro, J., Herrera, E., and Ramos, M.P. 2008. Validation of simple indexes to assess insulin sensitivity during pregnancy in Wistar and Sprague-Dawley rats. Am J Physiol Endocrinol Metab 295: E1269-76.

Cho, C.E., Pannia, E., Huot, P.S., Sanchez-Hernandez, D., Kubant, R., Dodington, D.W., Ward, W.E., Bazinet, R.P., and Anderson, G.H. 2015. Methyl vitamins contribute to obesogenic effects of a high multivitamin gestational diet and epigenetic alterations in hypothalamic feeding pathways in Wistar rat offspring. Mol Nutr Food Res 59: 476-89.

Cho, C.E., Sanchez-Hernandez, D., Reza-Lopez, S.A., Huot, P.S., Kim, Y.I., and Anderson, G.H. 2013a. High folate gestational and post-weaning diets alter hypothalamic feeding pathways by DNA methylation in Wistar rat offspring. Epigenetics 8.

Cho, C.E., Sanchez-Hernandez, D., Reza-Lopez, S.A., Huot, P.S., Kim, Y.I., and Anderson, G.H. 2013b. Obesogenic phenotype of offspring of dams fed a high multivitamin diet is prevented by a post-weaning high multivitamin or high folate diet. Int J Obes (Lond).

Colapinto, C.K., O'Connor, D.L., and Tremblay, M.S. 2011. Folate status of the population in the Canadian Health Measures Survey. Cmaj 183: E100-6.

Cutfield, W.S., Jefferies, C.A., Jackson, W.E., Robinson, E.M., and Hofman, P.L. 2003. Evaluation of HOMA and QUICKI as measures of insulin sensitivity in prepubertal children. Pediatr Diabetes 4: $119-25$.

De Wals, P., Tairou, F., Van Allen, M.I., Lowry, R.B., Evans, J.A., Van den Hof, M.C., Crowley, M., Uh, S.H., Zimmer, P., Sibbald, B., Fernandez, B., Lee, N.S., and Niyonsenga, T. 2008. Spina bifida before and after folic acid fortification in Canada. Birth Defects Res A Clin Mol Teratol 82: 622-6. 
De Wals, P., Tairou, F., Van Allen, M.I., Uh, S.H., Lowry, R.B., Sibbald, B., Evans, J.A., Van den Hof, M.C., Zimmer, P., Crowley, M., Fernandez, B., Lee, N.S., and Niyonsenga, T. 2007. Reduction in neural-tube defects after folic acid fortification in Canada. N Engl J Med 357: 135-42.

Duthie, S.J. 2010. Folate and cancer: how DNA damage, repair and methylation impact on colon carcinogenesis. J Inherit Metab Dis.

French, A.E., Grant, R., Weitzman, S., Ray, J.G., Vermeulen, M.J., Sung, L., Greenberg, M., and Koren, G. 2003. Folic acid food fortification is associated with a decline in neuroblastoma. Clin Pharmacol Ther 74: 288-94.

Gluckman, P.D. and Hanson, M.A. 2006. The Developmental Origins of Health and Disease: The Breadth and Importance of the Concept.In: E.M. Wintour and J.A. Owens (Ed.)^(Eds.), Early Life Origins of Health and Disease, pp. 1-7. New York: Eurekah.com, Springer Science+Business Media.

Gluckman, P.D., Hanson, M.A., Cooper, C., and Thornburg, K.L. 2008. Effect of in utero and earlylife conditions on adult health and disease. N Engl J Med 359: 61-73.

Green, N.S. 2002. Folic acid supplementation and prevention of birth defects. J Nutr 132: 2356S2360S.

Hanson, M., Godfrey, K.M., Lillycrop, K.A., Burdge, G.C., and Gluckman, P.D. 2011. Developmental plasticity and developmental origins of non-communicable disease: theoretical considerations and epigenetic mechanisms. Prog Biophys Mol Biol 106: 272-80.

Huot, P.S., Dodington, D.W., Mollard, R.C., Reza-Lopez, S.A., Sanchez-Hernandez, D., Cho, C.E., Kuk, J., Ward, W.E., and Anderson, G.H. 2013. High Folic Acid Intake during Pregnancy Lowers Body Weight and Reduces Femoral Area and Strength in Female Rat Offspring. J Osteoporos 2013: 154109.

IOM 1998. Dietary Reference Intakes for Thiamin, Riboflavin, Niacin, Vitamin B6, Folate, Vitamin B12, Pantothenic Acid, Biotin, and Choline. Washington, D.C.: The National Academies Press.

Kiefte-de Jong, J.C., Timmermans, S., Jaddoe, V.W., Hofman, A., Tiemeier, H., Steegers, E.A., de Jongste, J.C., and Moll, H.A. 2012. High circulating folate and vitamin B-12 concentrations in women during pregnancy are associated with increased prevalence of atopic dermatitis in their offspring. J Nutr 142: 731-8.

Kim, Y.I. 2005. Nutritional epigenetics: impact of folate deficiency on DNA methylation and colon cancer susceptibility. J Nutr 135: 2703-9.

Kim, Y.I. 2007. Folate and colorectal cancer: an evidence-based critical review. Mol Nutr Food Res 51: 267-92.

Kim, Y.I. 2008. Folic acid supplementation and cancer risk: point. Cancer Epidemiol Biomarkers Prev 17: 2220-5. 
Koren, G., Goh, Y.I., and Klieger, C. 2008. Folic acid: the right dose. Can Fam Physician 54: 15457.

Lagiou, P., Mucci, L., Tamimi, R., Kuper, H., Lagiou, A., Hsieh, C.C., and Trichopoulos, D. 2005. Micronutrient intake during pregnancy in relation to birth size. Eur J Nutr 44: 52-9.

Livak, K.J. and Schmittgen, T.D. 2001. Analysis of relative gene expression data using real-time quantitative PCR and the 2(-Delta Delta C(T)) Method. Methods 25: 402-8.

Ly, A., Lee, H., Chen, J., Sie, K.K., Renlund, R., Medline, A., Sohn, K.J., Croxford, R., Thompson, L.U., and Kim, Y.I. 2011. Effect of maternal and postweaning folic acid supplementation on mammary tumor risk in the offspring. Cancer Res 71: 988-97.

Marti-Carvajal, A., Pena-Marti, G., Comunian-Carrasco, G., Munoz-Navarro, S., Luco, M., MartiPena, A., and Medina-Laurentin, C. 2004. Prematurity and maternal folate deficiency: anemia during pregnancy study group results in Valencia, Venezuela. Arch Latinoam Nutr 54: 45-9.

Mills, J.L. and Signore, C. 2004. Neural tube defect rates before and after food fortification with folic acid. Birth Defects Res A Clin Mol Teratol 70: 844-5.

Molloy, A.M. and Scott, J.M. 1997. Microbiological assay for serum, plasma, and red cell folate using cryopreserved, microtiter plate method. Methods Enzymol 281: 43-53.

National Research Council (U.S.). Subcommittee on Laboratory Animal Nutrition. 1995. Nutrient requirements of laboratory animals. Washington, D.C.: National Academy of Sciences.

Obican, S.G., Finnell, R.H., Mills, J.L., Shaw, G.M., and Scialli, A.R. 2010. Folic acid in early pregnancy: a public health success story. Faseb J 24: 4167-74.

Olney, R.S. and Mulinare, J. 2002. Trends in neural tube defect prevalence, folic acid fortification, and vitamin supplement use. Semin Perinatol 26: 277-85.

Pfeiffer, C.M., Johnson, C.L., Jain, R.B., Yetley, E.A., Picciano, M.F., Rader, J.I., Fisher, K.D., Mulinare, J., and Osterloh, J.D. 2007. Trends in blood folate and vitamin B-12 concentrations in the United States, 1988 2004. Am J Clin Nutr 86: 718-27.

Rao, S., Yajnik, C.S., Kanade, A., Fall, C.H., Margetts, B.M., Jackson, A.A., Shier, R., Joshi, S., Rege, S., Lubree, H., and Desai, B. 2001. Intake of micronutrient-rich foods in rural Indian mothers is associated with the size of their babies at birth: Pune Maternal Nutrition Study. J Nutr 131: 121724.

Ray, J.G., Meier, C., Vermeulen, M.J., Boss, S., Wyatt, P.R., and Cole, D.E. 2002. Association of neural tube defects and folic acid food fortification in Canada. Lancet 360: 2047-8.

Scholl, T.O. 2008. Maternal nutrition before and during pregnancy. Nestle Nutr Workshop Ser Pediatr Program 61: 79-89.

Shea, B., Swinden, M.V., Ghogomu, E.T., Ortiz, Z., Katchamart, W., Rader, T., Bombardier, C., Wells, G.A., and Tugwell, P. 2014. Folic acid and folinic acid for reducing side effects in patients receiving methotrexate for rheumatoid arthritis. J Rheumatol 41: 1049-60. 
Shorter, K.R., Anderson, V., Cakora, P., Owen, A., Lo, K., Crossland, J., South, A.C., Felder, M.R., and Vrana, P.B. 2014. Pleiotropic effects of a methyl donor diet in a novel animal model. PLoS One 9: e104942.

Sie, K.K., Chen, J., Sohn, K.J., Croxford, R., Thompson, L.U., and Kim, Y.I. 2009. Folic acid supplementation provided in utero and during lactation reduces the number of terminal end buds of the developing mammary glands in the offspring. Cancer Lett 280: 72-7.

Sie, K.K., Medline, A., van Weel, J., Sohn, K.J., Choi, S.W., Croxford, R., and Kim, Y.I. 2011. Effect of maternal and postweaning folic acid supplementation on colorectal cancer risk in the offspring. Gut 60: 1687-94.

Sullivan, K.M., Ford, E.S., Azrak, M.F., and Mokdad, A.H. 2009. Multivitamin use in pregnant and nonpregnant women: results from the Behavioral Risk Factor Surveillance System. Public Health Rep 124: 384-90.

Szeto, I.M., Aziz, A., Das, P.J., Taha, A.Y., Okubo, N., Reza-Lopez, S., Giacca, A., and Anderson, G.H. 2008. High multivitamin intake by Wistar rats during pregnancy results in increased food intake and components of the metabolic syndrome in male offspring. Am J Physiol Regul Integr Comp Physiol 295: R575-82.

Szeto, I.M., Das, P.J., Aziz, A., and Anderson, G.H. 2009. Multivitamin supplementation of Wistar rats during pregnancy accelerates the development of obesity in offspring fed an obesogenic diet. Int J Obes (Lond) 33: 364-72.

Szeto, I.M., Payne, M.E., Jahan-mihan, A., Duan, J., and Anderson, G.H. 2010. Multivitamin supplementation during pregnancy alters body weight and macronutrient selection in Wistar rat offspring. Journal of Developmental Origins of Health and Disease 1: 386-395.

Szeto, I.M.Y., Huot, P.S.P., Reza-Lopez, S.A., Jahan-Mihan, A., and Anderson, G.H. 2011. The effect of high multivitamin diet during pregnancy on food intake and glucose metabolism in Wistar rat offspring fed low-vitamin diets post weaning. Journal of Developmental Origins of Health and Disease 2: 302-310.

Torrens, C., Brawley, L., Anthony, F.W., Dance, C.S., Dunn, R., Jackson, A.A., Poston, L., and Hanson, M.A. 2006. Folate supplementation during pregnancy improves offspring cardiovascular dysfunction induced by protein restriction. Hypertension 47: 982-7.

Walzem, R.L. and Clifford, A.J. 1988. Folate deficiency in rats fed diets containing free amino acids or intact proteins. J Nutr 118: 1089-96.

Warzak, D.A., Johnson, S.A., Ellersieck, M.R., Roberts, R.M., Zhang, X., Ho, S.M., and Rosenfeld, C.S. 2015. Effects of post-weaning diet on metabolic parameters and DNA methylation status of the cryptic promoter in the A(vy) allele of viable yellow mice. J Nutr Biochem 26: 667-74.

Waterland, R.A. and Michels, K.B. 2007. Epigenetic epidemiology of the developmental origins hypothesis. Annu Rev Nutr 27: 363-88. 
Whitrow, M.J., Moore, V.M., Rumbold, A.R., and Davies, M.J. 2009. Effect of supplemental folic acid in pregnancy on childhood asthma: a prospective birth cohort study. Am J Epidemiol 170: 1486-93.

Wilson, R.D., Johnson, J.A., Wyatt, P., Allen, V., Gagnon, A., Langlois, S., Blight, C., Audibert, F., Desilets, V., Brock, J.A., Koren, G., Goh, Y.I., Nguyen, P., and Kapur, B. 2007. Pre-conceptional vitamin/folic acid supplementation 2007: the use of folic acid in combination with a multivitamin supplement for the prevention of neural tube defects and other congenital anomalies. J Obstet Gynaecol Can 29: 1003-26.

Wright, A.J., Dainty, J.R., and Finglas, P.M. 2007. Folic acid metabolism in human subjects revisited: potential implications for proposed mandatory folic acid fortification in the UK. Br J Nutr 98: 667-75.

Yajnik, C.S., Deshpande, S.S., Jackson, A.A., Refsum, H., Rao, S., Fisher, D.J., Bhat, D.S., Naik, S.S., Coyaji, K.J., Joglekar, C.V., Joshi, N., Lubree, H.G., Deshpande, V.U., Rege, S.S., and Fall, C.H. 2008. Vitamin B12 and folate concentrations during pregnancy and insulin resistance in the offspring: the Pune Maternal Nutrition Study. Diabetologia 51: 29-38. 


\section{Table 1}

Fasting folate status, glucose, and insulin concentrations of male and female offspring at 25 weeks post-weaning (study termination) ${ }^{1}$

\begin{tabular}{|c|c|c|c|c|c|c|c|c|c|c|c|c|c|}
\hline \multirow[t]{3}{*}{$\begin{array}{l}\text { Dam } \\
\text { Diet }\end{array}$} & \multirow[t]{3}{*}{$\begin{array}{l}\text { Pup } \\
\text { Diet }\end{array}$} & \multirow{2}{*}{\multicolumn{2}{|c|}{$\begin{array}{l}\text { Plasma } \\
\text { Folate }\end{array}$}} & \multirow{2}{*}{\multicolumn{2}{|c|}{$\begin{array}{l}\text { Liver } \\
\text { Folate }\end{array}$}} & \multirow{2}{*}{\multicolumn{2}{|c|}{$\begin{array}{l}\text { Blood } \\
\text { Glucose }\end{array}$}} & \multirow{2}{*}{\multicolumn{2}{|c|}{$\begin{array}{l}\text { Plasma } \\
\text { Insulin }\end{array}$}} & \multicolumn{2}{|c|}{$\begin{array}{c}\text { Insulin } \\
\text { Resistance } \\
\text { Index }\end{array}$} & \multirow{2}{*}{\multicolumn{2}{|c|}{ QUICKI }} \\
\hline & & & & & & & & & & \multicolumn{2}{|c|}{ Males } & & \\
\hline & & $\begin{array}{r}\text { Mean } \\
\text { (ng }\end{array}$ & $\begin{array}{l}\text { SE } \\
n L)\end{array}$ & $\begin{array}{l}\text { Mean } \\
(\mu \mathrm{g} / \\
\text { tiss }\end{array}$ & $\begin{array}{l}\text { SE } \\
\text { of } \\
\text { ) }\end{array}$ & $\begin{array}{l}\text { Mean } \\
(\mathrm{mmc}\end{array}$ & $\begin{array}{l}\text { SE } \\
\text { l/L) }\end{array}$ & $\begin{array}{l}\text { Mean } \\
\text { (ng / }\end{array}$ & SE & Mean & SE & Mean & SE \\
\hline RFol & RFol & $35.2^{c}$ & 2.4 & 6.8 & 0.2 & 5.5 & 0.2 & 2.5 & 0.4 & $12.5^{A B}$ & 3.8 & $0.273^{A B}$ & 0.009 \\
\hline RFol & 2.5HFol & $62.5^{\mathrm{B}}$ & 3.0 & 9.2 & 0.3 & 5.0 & 0.2 & 2.2 & 0.3 & $11.0^{A B}$ & 0.6 & $0.271^{A B}$ & 0.002 \\
\hline $2.5 \mathrm{HFol}$ & RFol & $24.7^{\mathrm{D}}$ & 1.9 & 7.7 & 0.3 & 5.9 & 0.1 & 2.9 & 0.4 & $17.1^{\mathrm{A}}$ & 3.2 & $0.260^{B}$ & 0.006 \\
\hline $2.5 \mathrm{HFol}$ & $2.5 \mathrm{HFol}$ & $76.2^{A}$ & 2.9 & 9.9 & 0.5 & 5.4 & 0.2 & 1.7 & 0.3 & $7.8^{B}$ & 0.9 & $0.284^{A}$ & 0.005 \\
\hline \multirow{2}{*}{\multicolumn{2}{|c|}{$\begin{array}{l}\text { Dam Diet } \\
\text { Pup Diet }\end{array}$}} & \multirow{2}{*}{\multicolumn{2}{|c|}{$\begin{array}{c}\text { NS } \\
P<0.001\end{array}$}} & \multirow{2}{*}{\multicolumn{2}{|c|}{$\begin{array}{c}P<0.05 \\
P<0.0001\end{array}$}} & \multirow{2}{*}{\multicolumn{2}{|c|}{$\begin{array}{l}P<0.10 \\
P<0.05\end{array}$}} & \multirow{2}{*}{\multicolumn{2}{|c|}{$\begin{array}{c}\text { NS } \\
P<0.05\end{array}$}} & \multirow{2}{*}{\multicolumn{2}{|c|}{$\begin{array}{c}\text { NS } \\
P<0.05\end{array}$}} & \multirow{2}{*}{\multicolumn{2}{|c|}{$\begin{array}{c}\text { NS } \\
P=0.05\end{array}$}} \\
\hline & & & & & & & & & & & & & \\
\hline \multicolumn{2}{|c|}{$\begin{array}{c}\text { Dam Diet } \times \\
\text { Pup Diet }\end{array}$} & \multicolumn{2}{|c|}{$P<0.001$} & \multicolumn{2}{|c|}{ NS } & \multicolumn{2}{|c|}{ NS } & \multicolumn{2}{|c|}{ NS } & \multicolumn{2}{|c|}{$P<0.05$} & \multicolumn{2}{|c|}{$P<0.05$} \\
\hline
\end{tabular}

\section{Females}

Mean SE Mean SE Mean SE Mean SE Mean SE Mean SE

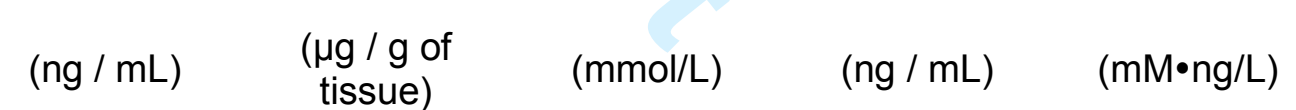

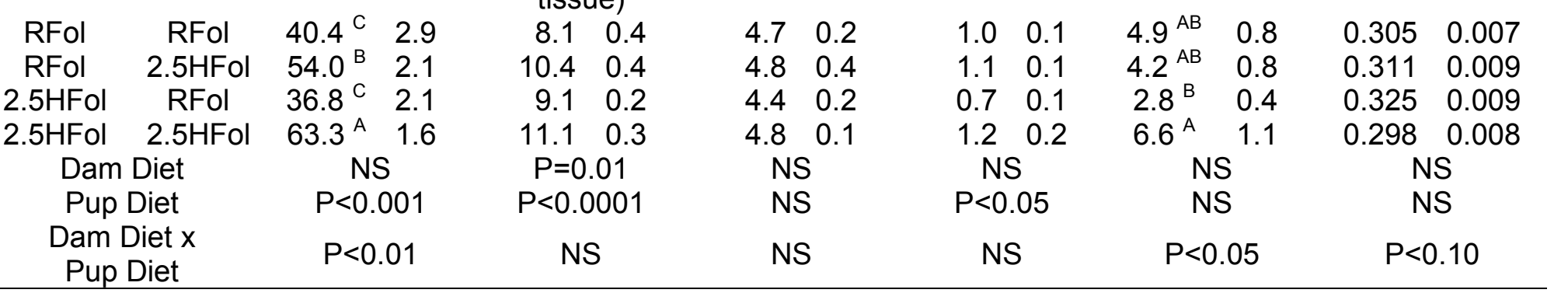

${ }^{1}$ Data are means $\pm \mathrm{SE} ; \mathrm{N}=12-15$ /group. Insulin resistance index $=$ fasting glucose $\times$ fasting insulin. Data were analyzed by 2-way ANOVA with dam diet and pup diet as main factors, followed by post-hoc Tukey's test if a significant interaction was found. Non-normally distributed data (insulin resistance index) was log-transformed for analysis. Means with different superscripts are significantly different, $\mathrm{P}<0.0001$ (males), $\mathrm{P}<0.05$ (females).

RFol, control, basal dietary requirement; 2.5HFol, 2.5x folic acid supplemented diet; QUICKI, quantitative insulin sensitivity check index; NS, not significant. 


\section{Figure captions}

\section{Figure 1.}

Title: Body weights from 1 to 25 weeks post-weaning of $\boldsymbol{A}$. Male offspring and $\boldsymbol{B}$. Female offspring.

\section{Legend:}

Data are means $\pm \mathrm{SE}$, analyzed by PROC MIXED (dam diet, pup diet and time as main factors); $\mathrm{N}=$ 12-15/group

A: dam diet: NS; pup diet: NS; time: $\mathrm{P}<0.0001$; dam $\operatorname{diet} \times$ pup $\operatorname{diet}: \mathrm{NS}$; $\operatorname{dam} \operatorname{diet} \times \operatorname{time}: \mathrm{P}<0.0001$; pup diet $\times$ time: $\mathrm{P}<0.05$; dam diet $\times$ pup $\operatorname{diet} \times$ time: NS.

B: dam diet: NS; pup diet: NS; time: $\mathrm{P}<0.0001$; dam diet $\times$ pup diet: NS; dam $\operatorname{diet} \times$ time: $\mathrm{P}<0.0001$; Pup diet $\times$ time: NS; dam diet $\times$ pup $\operatorname{diet} \times$ time: NS.

RFol, control, basal dietary requirement; $2.5 \mathrm{HFol}, 2.5 \mathrm{x}$ folic acid supplemented diet; NS, not significant.

\section{Figure 2.}

Title: 1-hour glucose loading at 20 weeks post-weaning of $\boldsymbol{A}$. Male offspring and $\boldsymbol{B}$. Female offspring

\section{Legend:}

Glucose gavage: $0.375 \mathrm{~g}$ glucose $/ 1 \mathrm{~mL} ; 5 \mathrm{~g} / \mathrm{kg}$ body weight. Data are means $\pm \mathrm{SE} ; \mathrm{N}=8-10 /$ group.

A: *dam diet: $\mathrm{P}<0.10$ : pup diet: $\mathrm{P}<0.05$; dam $\operatorname{diet} \times$ pup diet: NS

**dam diet: $\mathrm{P}<0.01$; pup diet: NS; dam diet $\times$ pup diet: NS

All other time points: NS

B: dam diet: NS; pup diet: NS; dam diet $\times$ pup diet: NS for all time points.

RFol, control, basal dietary requirement; 2.5HFol, $2.5 \mathrm{x}$ folic acid supplemented diet; NS, not significant. 


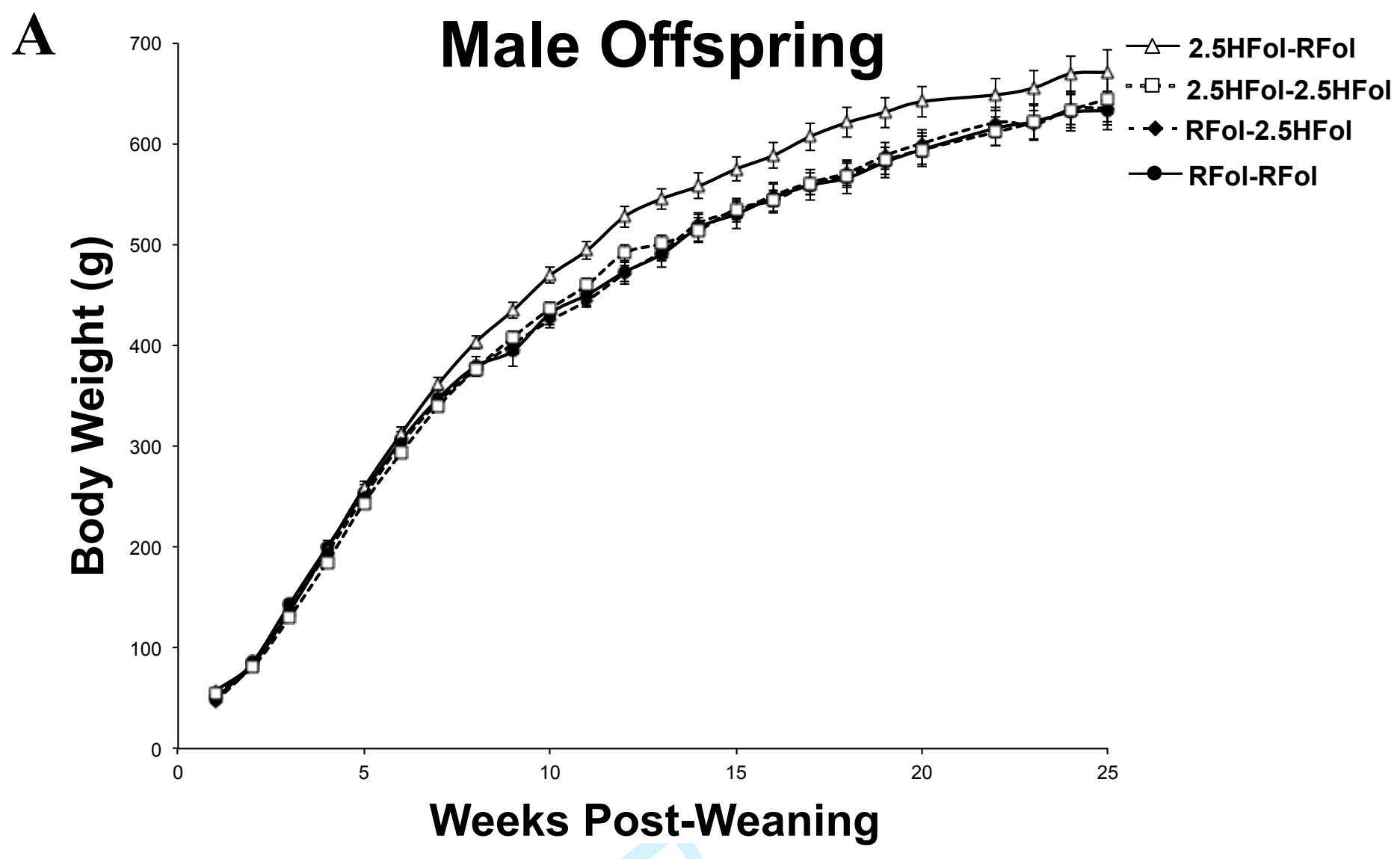

B

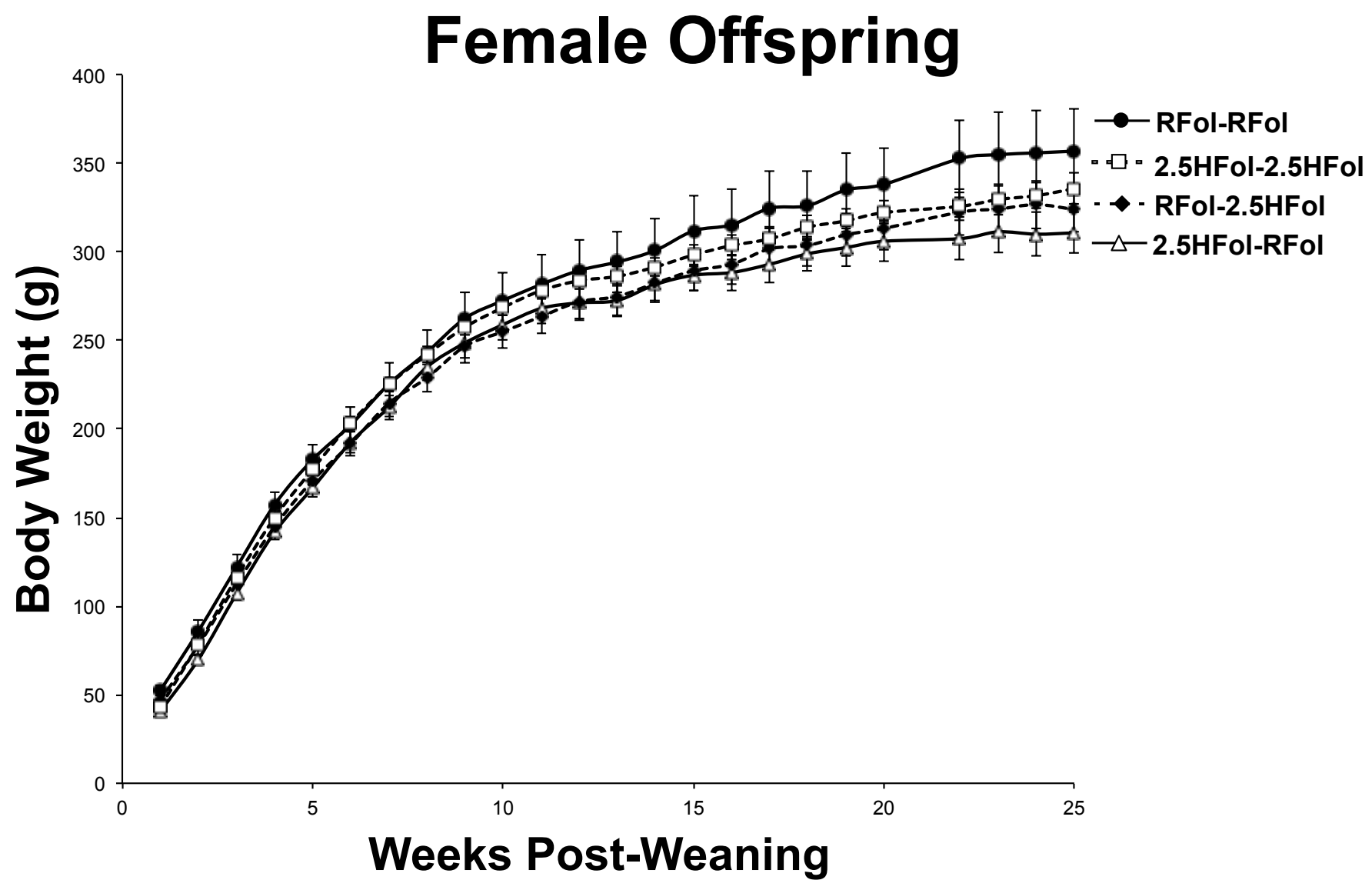

Figure 1 
A

Male Offspring

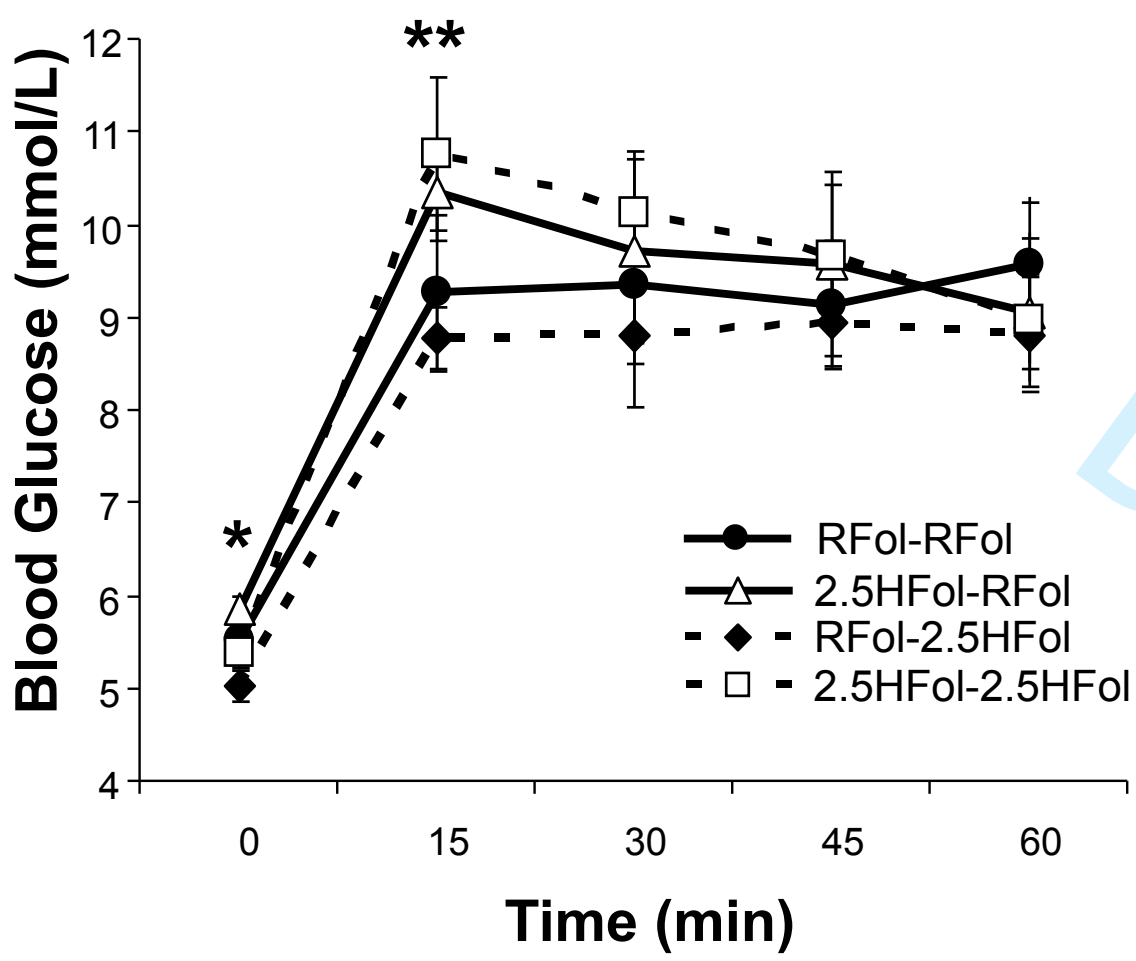

B

Female Offspring

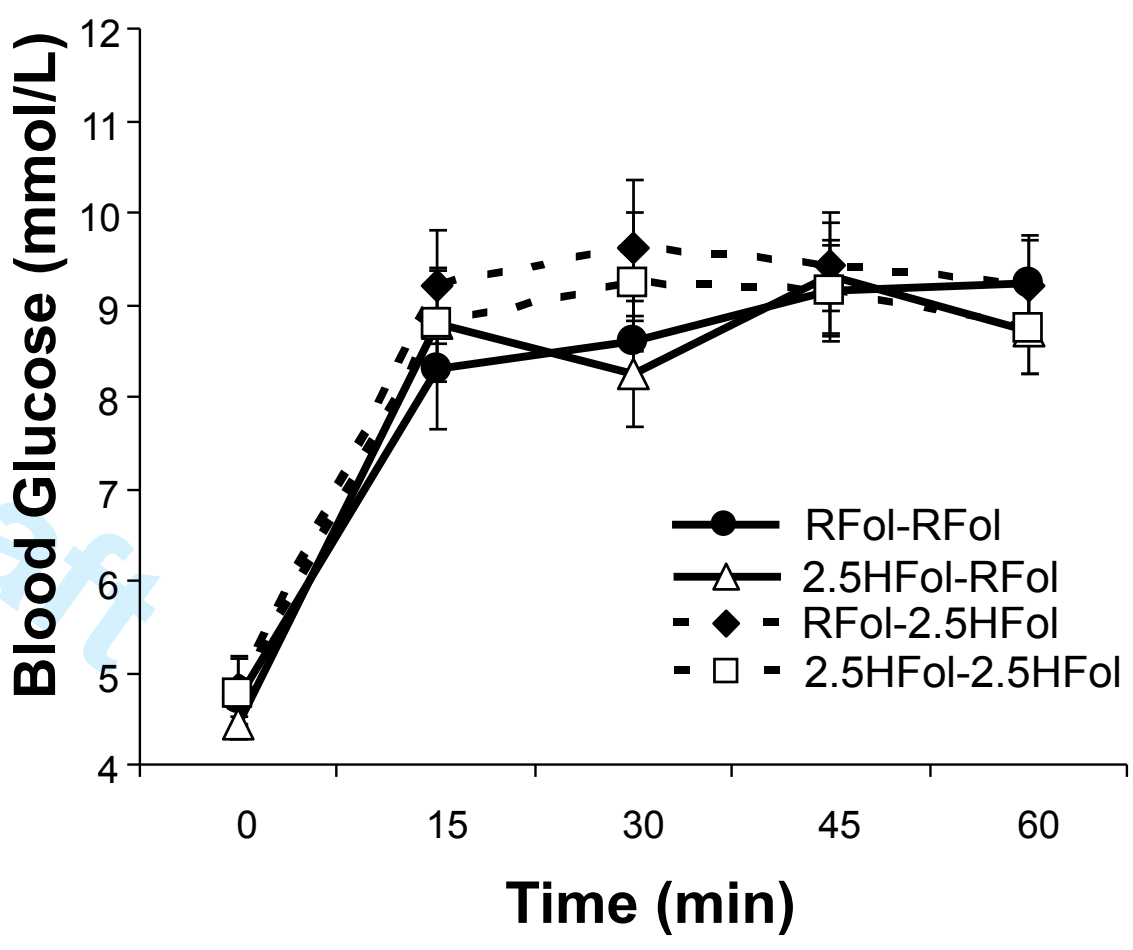

Figure 2 